\title{
Distribution and Abundance of American Eels in the White Oak River Estuary, North Carolina
}

\author{
Joseph E. Hightower ${ }^{1, *}$ and Cynthia Nesnow ${ }^{2,3}$
}

\begin{abstract}
Apparent widespread declines in abundance of Anguilla rostrata (American eel) have reinforced the need for information regarding its life history and status. We used commercial eel pots and crab (peeler) pots to examine the distribution, condition, and abundance of American eels within the White Oak River estuary, NC, during summers of 2002-2003. Catch of American eels per overnight set was $0.35(\mathrm{SE}=0.045)$ in 2002 and $0.49(\mathrm{SE}=0.044)$ in 2003. There was not a significant linear relationship between catch per set and depth in 2002 (P $=0.31$, depth range $0.9-3.4 \mathrm{~m})$ or $2003(\mathrm{P}=0.18$, depth range $0.6-3.4 \mathrm{~m})$. American eels from the White Oak River were in good condition, based on the slope of a length-weight relationship (3.41) compared to the median slope (3.15) from other systems. Estimates of population density from grid sampling in 2003 (300 mm and larger: 4.0-13.8 per ha) were similar to estimates for the Hudson River estuary, but substantially less than estimates from other (smaller) systems including tidal creeks within estuaries. Density estimates from coastal waters can be used with harvest records to examine whether overfishing has contributed to the recent apparent declines in American eel abundance.
\end{abstract}

\section{Introduction}

Anguilla rostrata LeSueur (American eel) is an ecological generalist that is widely distributed along the eastern coast of North America (Haro et al. 2000, Helfman et al. 1984). It is a catadromous species that matures in freshwater, spawns in the Sargasso Sea, and dies after spawning (Haro et al. 2000, McCleave et al. 1987, Tesch 1977). The leptocephalus larvae migrate northward and eastward through passive drift for about 1 year before metamorphosing into glass eels (Helfman et al. 1987, McCleave et al. 1987). As glass eels enter coastal rivers and estuaries, they transform into elvers (Helfman et al. 1987). Once in a river or creek, they move into the yellow phase of their life history (sexually immature juveniles of intermediate size), which is the primary feeding and growth stage (Jessop 2000, Oliveira 1997). Sexual maturity typically occurs at a length and age of 300-400 mm and 513 years for males and 500-700 mm and 9-17 years for females (Helfman et al. 1987, Oliveira 1999, Oliveira and McCleave 2000). At the final metamorphosis, American eels enter the silver phase and begin their migration to the

\footnotetext{
${ }^{1}$ US Geological Survey, North Carolina Cooperative Fisheries and Wildlife Research Unit, Department of Zoology, North Carolina State University, Raleigh, NC 27695-7617. ${ }^{2}$ North Carolina Cooperative Fish and Wildlife Research Unit, Department of Zoology, North Carolina State University, Raleigh, NC 27695-7617. ${ }^{3}$ Current address - USDA, APHIS, VS Eastern Regional Office, Raleigh, NC 27606. *Corresponding author - jhightower@ncsu.edu.
} 
Sargasso Sea. American eels are assumed to be a panmictic (randomly breeding) population due to their catadromous life-history strategy (Haro et al. 2000). This assumption is supported by recent genetic analyses (Wirth and Bernatchez 2003).

The development in the 1990s of substantial commercial fisheries for elvers for overseas aquaculture, along with various indicators of declining abundance, have led to concerns about the status and management of American eel populations (Dixon 2003, Haro et al. 2000, Jessop 2000). Population indices from the eastern United States and Canada suggest a widespread decline in abundance, potentially due to habitat loss, overfishing, parasitism, pollution, or a change in oceanic conditions (Haro et al. 2000). Habitat loss could be substantial; Busch et al. (1998) estimated that about $84 \%$ of the river and stream habitat once available to migratory fishes is now located above dams.

Population size or density of American eels has been estimated in many systems, ranging from tidal creeks and estuaries to inland first-order streams. Most of these estimates are from wadeable sites that are often closed off using block nets. Only a few studies have been conducted within estuaries (e.g., Bozeman et al. 1985, Ford and Mercer 1986, Morrison and Secor 2004), even though most harvest of yellow eels occurs in coastal waters (ASMFC 2000). The objectives of this study were to examine the distribution, condition, and abundance of American eels within the White Oak River estuary, NC. Information about American eel abundance and life history in a coastal estuary should aid in evaluating the impact of fishing versus other potential causes for population declines.

\section{Methods}

Sampling was conducted during May-June 2002 and July-August 2003 at estuarine sites within the White Oak River (Fig. 1), a brackish-freshwater river that lies entirely in the southern outer coastal plain of North Carolina (NCDENR 2005). Land to the west of the river is in private ownership, whereas much of the watershed to the east is contained within the Croatan National Forest. Most of the surrounding land area is forested, except for substantial agricultural land use on the western side of the basin (NCDENR 2001). This section of the river is bordered by saltwater marshes and has generally good water quality, although dissolved oxygen, $\mathrm{pH}$, and fecal coliform standards were exceeded in more than $20 \%$ of observations (NCDENR 2005). Excess nutrient inputs to the mainstem river (especially runoff from subdivisions and agricultural operations) are of concern (NCDENR 2001).

American eels were captured primarily using commercial eel pots made of $1.3-\mathrm{cm}$ wire mesh and measuring $62 \mathrm{~cm}$ in length with a 24-cm diameter circular entry ring. Typically, pots were set in late afternoon with fresh Callinectes sapidus Rathbun (blue crab) as bait and checked the following morning. Location (UTM coordinates) and water depth were recorded at 
each site a pot was fished. In 2002, American eels were also obtained from a commercial crabber (R. Howell, Swansboro, NC), who fished about 200 peeler crab pots daily in this section of the estuary. Peeler pots, which capture female blue crabs that are about to molt, have $2.54-\mathrm{cm}$ mesh and are not fitted with escape rings because there is no minimum-size regulation for peeler crabs.

In 2002, there were 283 overnight sets of commercial eel pots on 12 occasions between May 16 and June 6. Pots were fished along the shoreline (Fig. 1) at depths ranging from 0.9 to $3.4 \mathrm{~m}$ (mean depth $=1.6 \mathrm{~m}$ ). The study area for the capture-recapture experiment was assumed to be a $1.29-\mathrm{km}^{2}$ area downstream of Stella, NC, and demarcated by the NC Division of Marine Fisheries upper boundary for commercial shrimping to the south and a peninsula of land to the north (Fig. 1). American eels captured in peeler pots were not included in the capture-recapture analyses because the specific location of each capture was not recorded.

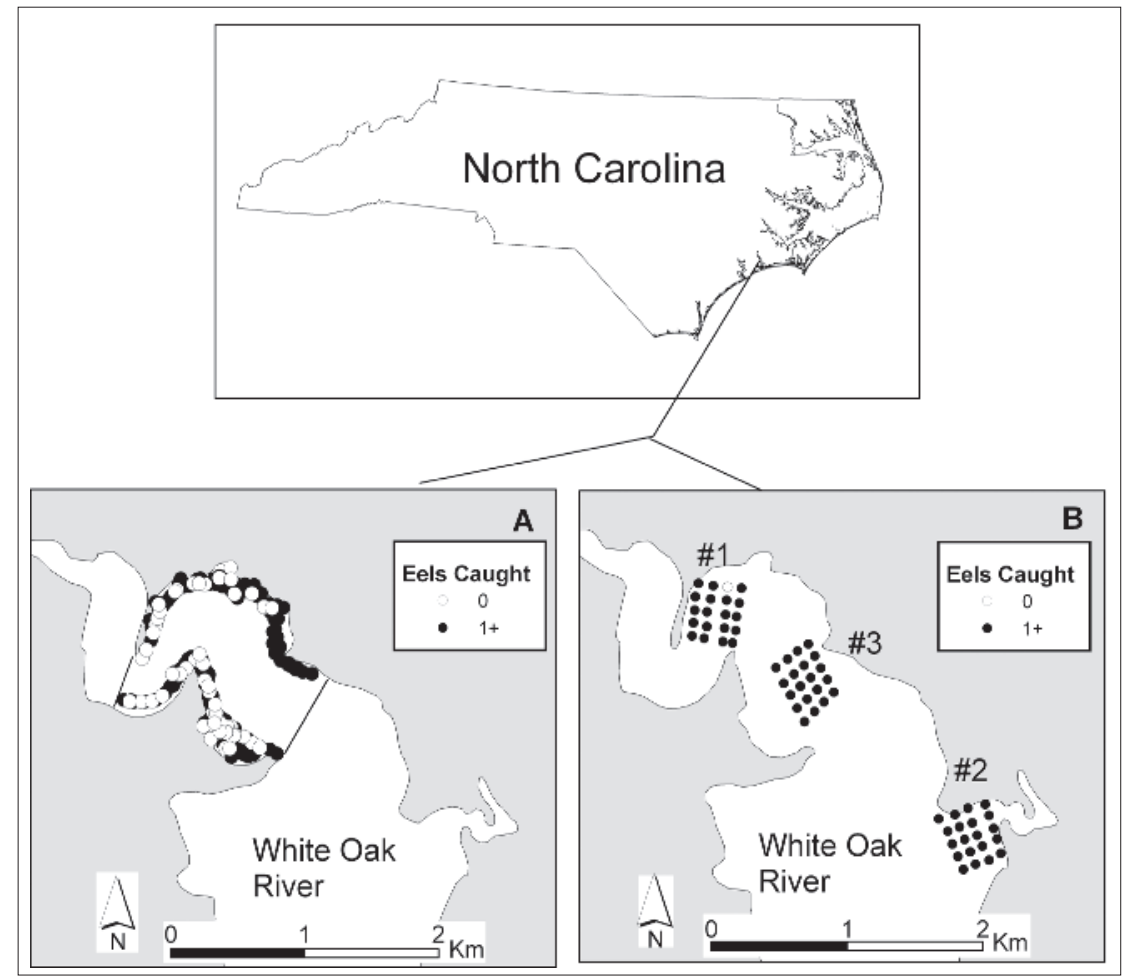

Figure 1. Location of White Oak River on North Carolina coastline. Inset A shows 2002 capture-recapture study area (denoted by linesacross the river channel) and eel pot sampling sites where catch of American eels was zero (open circles) or greater than zero (closed circles). Inset B shows grid design for 2003 capture-recapture studies. American eels were captured at every grid location except the open circle in grid \#1. Numbers denote the order in which grids were sampled (\#1: 15-28 July, \#2: 29 July-8 August, \#3: 10-19 August). 
In 2003, 572 sets were made on 29 occasions between July 15 and August 19 using commercial eel pots fished at depths ranging from 0.6 to $3.4 \mathrm{~m}$ (mean depth $=1.1 \mathrm{~m}$ ). Most sets (434 of 572) were overnight, but 113 were 2-day sets and 25 were 3 -day sets. A grid design (Morrison and Secor 2004) was adopted for 2003 in order to characterize movement patterns more rigorously. We established grids with four columns, five rows, and a spacing of $100 \mathrm{~m}$ between pots (Fig. 1). The grid spacing was thought to be important because Morrison and Secor (2004) reported that American eels in the Hudson River were attracted to a bait plume and immigrated into their grids of baited eel pots. They attempted to define a grid spacing so that pots would be sampling the entire grid but would not have overlapping areas of attraction. They concluded that a spacing of 200 meters would have low interference between pots, but would still insure complete coverage of the grid. The average distance between our capture and recapture sites in 2002 was 185 m (see Results). Using a grid spacing of $100 \mathrm{~m}$ in 2003 may have resulted in some interference between pots, but should provide more detailed information about movements. We used three grids, with the order of grids designed to determine whether American eels marked upstream or downstream of the current grid site would migrate into that grid. Capture-recapture estimates of population size and density were made separately for each grid, so that an American eel was considered unmarked until captured within that grid. We converted each set of capture histories into a summary table referred to as a full-m array (Burnham et al. 1987), and used that summary table to calculate mean recapture rate for each number of days at large.

Captured American eels were measured (total length) to the nearest $\mathrm{mm}$ and weighed to the nearest $25 \mathrm{~g}$. Following the technique described by Sorensen et al. (1983), each unmarked American eel received an individual, three-digit freeze brand on the left midline using liquid nitrogen and a small slotted cattle brander (Everhot Manufacturing Company, Maywood, IL). After processing and recovery, American eels were released in the same area where trapped.

Statistical analyses were done using SAS JMP ${ }^{\odot}$ software and a significance level of $\alpha=0.05$. Correlation analysis was used to determine if catchper-unit-effort (CPUE) was affected by depth at the sampling location, and whether distance moved between capture and recapture sites was affected by time at large, length at tagging, or weight at tagging. A one-way analysis of variance (ANOVA) was used to test whether CPUE differed for 1-, 2-, and 3day soak times. Information about the factors affecting catch rates and movements will aid in developing an appropriate capture-recapture design for American eels. Length and weight data from initial captures were used to construct a $\log _{10}$-scale length-weight relationship as a measure of summer condition. An analysis of covariance was used to test for differences between years in the length-weight relationship. A t-test was used to compare 
mean lengths of American eels captured in commercial eel pots and crab peeler pots. Summer movement patterns for recaptured American eels were examined using ArcView GIS software with the Animal Movements extension (Hooge and Eichenlaub 1997).

Estimates of population size were made using MARK capture-recapture software (available at http://www.cnr.colostate.edu/ gwhite/mark/ mark.htm; Cooch and White 2003). The key question to address was whether a closed or open population model was more appropriate (Otis et al. 1978). Morrison and Secor (2004) detected immigration of American eels into grids of baited eel pots fished in the Hudson River estuary, and used open population models to estimate abundance. These open models are more correct in biological terms, but are also more demanding because of the increased number of parameters to estimate. We used closed models because our capture histories were relatively sparse and because our data indicated that most movement in the White Oak River estuary was over short distances (see Results and Discussion sections). If substantial immigration occurred, our estimates of population density would be too high. Also, because of the sparse capture histories, we considered only simple models with capture probabilities equal for initial-capture and recapture events.

Alternative models were compared using Akaike's Information Criterion (AIC), as corrected for small sample size (AICc; Burnham and Anderson 1998). The AICc criterion is useful for selecting the model that best explains the variation in the data with the fewest parameters (Cooch and White 2003). AICc values are on a relative scale, so alternative models can be compared using differences in AICc values ( $\triangle \mathrm{AICc}$ ). Models having a $\triangle \mathrm{AICc}$ within 1-2 of the best model have substantial support, whereas those with a $\Delta \mathrm{AICc}$ value of 3-7 have considerably less support (Burnham and Anderson 1998). Models with a $\triangle \mathrm{AICc}>10$ have essentially no support and fail to explain some substantial structure in the data.

\section{Results}

Excluding within-year recaptures, 488 American eels were captured during the two years $\left(\mathrm{N}_{2002}=270, \mathrm{~N}_{2003}=218\right)$. We did not observe in 2003 any American eels that had been freeze-branded in 2002. If the marks were not retained between years, some of the 218 individuals from 2003 may have been previously captured. Total length ranged from 224 to $709 \mathrm{~mm}(\mathrm{~N}=$ 487 ) and weight ranged from 25 to $800 \mathrm{~g}(\mathrm{~N}=297)$. Based on length and weight data for 296 individuals, there was a significant overall lengthweight relationship $\left(\mathrm{r}^{2}=0.85, \mathrm{P}<0.0001\right)$. The slope was not different between years, although intercepts differed significantly:

2002: $\log _{10}$ weight $=-6.616+3.408 \log _{10}$ total length

2003: $\log _{10}$ weight $=-6.683+3.408 \log _{10}$ total length

The higher intercept that we observed for 2002 may have been due to the earlier sampling (mid-May to early June) relative to 2003. 
American eels were caught in 66 of 283 overnight sets (23\%) of commercial eel pots in 2002, resulting in a total catch of 100 and an average CPUE of 0.35 American eels per set $(\mathrm{SE}=0.045)$. Of the 100 captures, 19 were recaptures of previously marked individuals. There was not a significant linear relationship between catch per set and depth $(\mathrm{P}=0.31)$. The distance moved between capture and recapture sites in 2002 ranged from 52 to 1204 $\mathrm{m}$ and averaged $185 \mathrm{~m}(\mathrm{SE}=58.0 \mathrm{~m})$. There was not a significant correlation between distance moved and time at large $(\mathrm{P}=0.22)$, length at tagging $(\mathrm{P}=$ $0.58)$, or weight at tagging $(\mathrm{P}=0.48)$. All but one recapture occurred on the same shoreline as the initial capture (Fig. 2). Days at large for recaptured individuals ranged from 1 to 15 .

There were 221 American eels caught in commercial peeler pots fished from April to June 2002. American eels captured in the larger-mesh peeler pots were substantially larger than those captured in the eel pots ( mean $=422$ $\mathrm{mm}$ for eel pots, mean $=544 \mathrm{~mm}$ for peeler pots; Fig. 3 ).

In 2003, American eels were caught in 211 of 572 sets (37\%), resulting in a total catch of 317 . Of the 217 different individuals captured, 142 were caught once, 56 were caught twice, 15 were caught three times, and 4 were caught four times. The size distribution was similar to that observed in eel-pot sampling during 2002 (Fig. 3). When grouped into daily intervals, there was a significant difference in CPUE for 1-, 2-, and 3-day sets. CPUE was 0.49 American eels/ set $(\mathrm{SE}=0.044)$ for 434 one-day (overnight) sets, $0.79(\mathrm{SE}=0.087)$ for 113 two-day sets, and $0.56(\mathrm{SE}=0.184)$ for 25 three-day sets. There was not a significant linear relationship between catch per set and depth $(\mathrm{P}=0.18)$.

Estimates of population size for 2002 were similar for a model allowing time-specific capture probabilities $(\mathrm{N}=204.6,95 \% \mathrm{CI}=149-307)$ and a reduced model with capture probability constant over time $(\mathrm{N}=209.8,95 \%$ $\mathrm{CI}=152-316)$. These estimates would apply to the size range vulnerable to capture by eel pots, or about $300 \mathrm{~mm}$ and larger. Capture probabilities for the full model were low and variable (Fig. 4). A reduced model with constant capture probability had no support based on a $\triangle \mathrm{AICc}$ value $>10$. Based on the full model, the estimated density of American eels ( $\geq 300 \mathrm{~mm}$ ) within the study area was 2.0 per ha, assuming that all depths were effectively sampled and used equally.

In 2003, there were 11 sampling occasions (days) for grid \#1 with 48 captures of 32 different individuals. For grid \#2, there were 10 occasions and 148 captures of 101 different individuals. For grid \#3, there were 8 occasions and 119 captures of 89 different individuals. Morrison and Secor (2004) reported temporary trap-shy behavior for American eels at large $1 \mathrm{~d}$ after tagging; however, we did not find any indication of a lower recapture rate for newly tagged individuals. Based on averages over the three grids, mean recapture rates were $0.11,0.13,0.09,0.02,0.02,0.04$, and 0.02 for tagged American eels at large for 1-7 days, respectively.

Most recaptures were of American eels marked within the same grid (Fig. 2). None of the 75 American eels recaptured in grid \#2 had been 
marked in grid \#1 (a distance of about $2.5 \mathrm{~km}$ ). Of the 35 recaptures in grid \#3, two had been marked in grid \#2 (a distance of about $1.7 \mathrm{~km}$ ) and 3 had been marked in grid \#1 (a distance of about $0.8 \mathrm{~km}$ ). For the capturerecapture estimate in grid \#3, the animals first marked in another grid were treated as unmarked at the first capture in grid \#3.

For grid \#1, the best model used a constant capture probability. Estimated population size within the grid was $50.0(95 \% \mathrm{CI}=39-76)$, with an

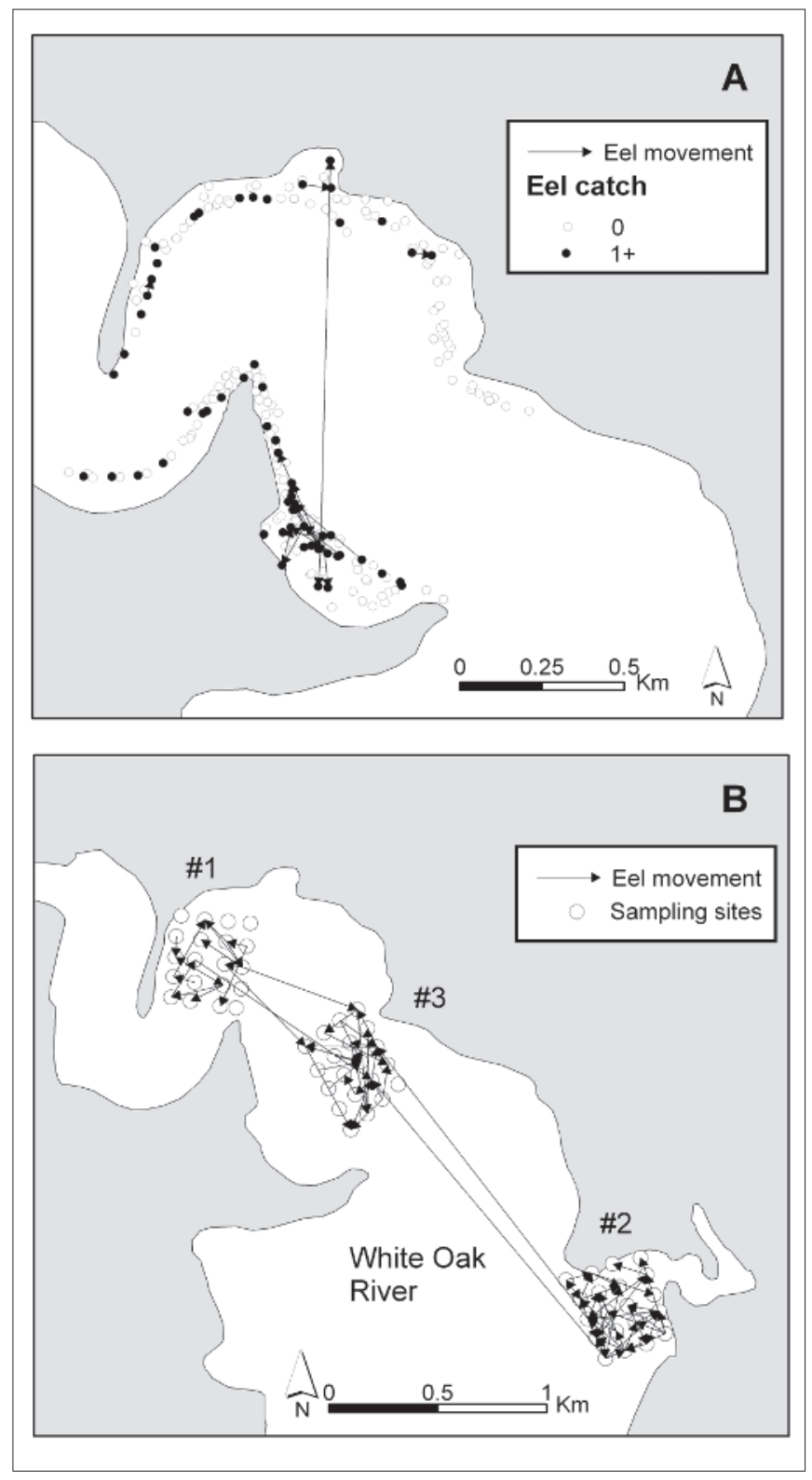

Figure 2. Movement of American eels in the White Oak River, NC, during May-June 2002 (panel A) and July - A u gu s t 2003 (panel B). Open circles in panel A denote all 2002 sampling sites. Grid numbers in panel $B$ denote the order in which sampling was done. 
estimated capture probability of $0.08(95 \% \mathrm{CI}=0.06-0.13)$. These estimates would apply to American eels vulnerable to capture by eel pots, or about 300 $\mathrm{mm}$ and larger. The model with time-specific capture probabilities was lower ranked but still feasible $(\triangle \mathrm{AICc}=1.89)$. It resulted in a very similar estimate of population size $(\mathrm{N}=48.6,95 \% \mathrm{CI}=39-74)$ and capture probabilities ranging from 0.02 to 0.21 (Fig. 5). Based on the highest-ranked model, the estimated density of American eels (300 mm and larger) within grid \#1 was 4.0 per ha.

For grid \#2, the best model allowed capture probabilities to vary over time. For that model, estimated population size within the grid was 161.8

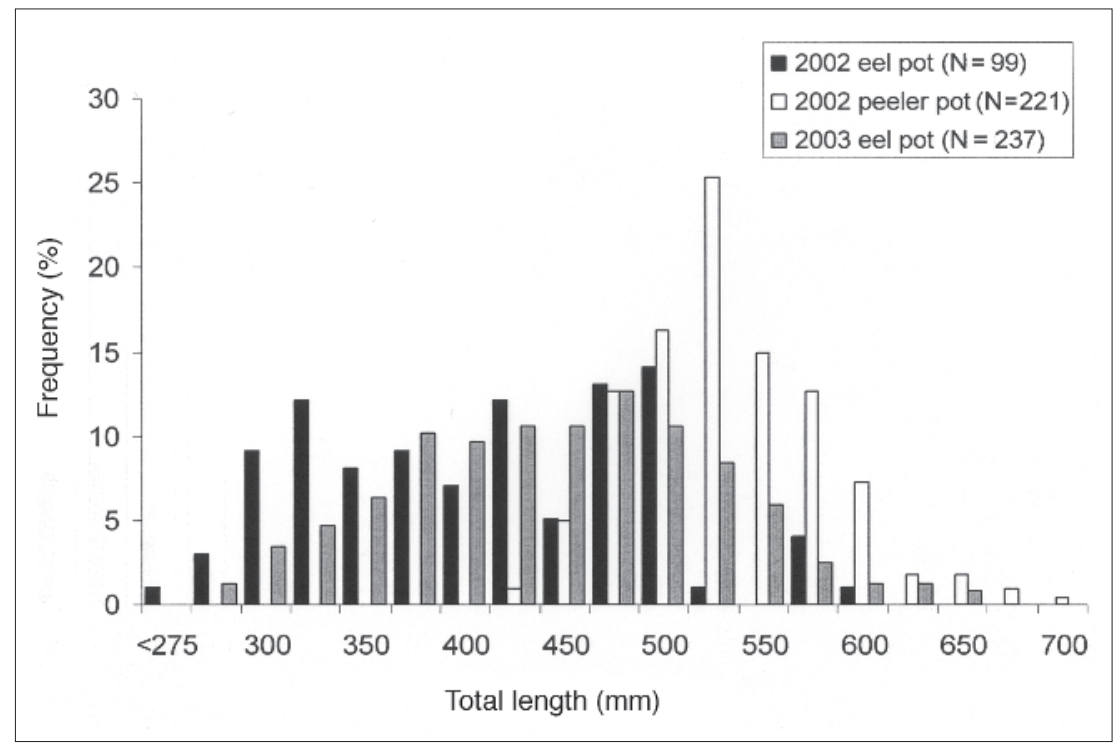

Figure 3. Frequency distributions for total length of American eels captured in the White Oak River, NC, using standard eel pots and peeler crab pots during 2002 and eel pots during 2003 .

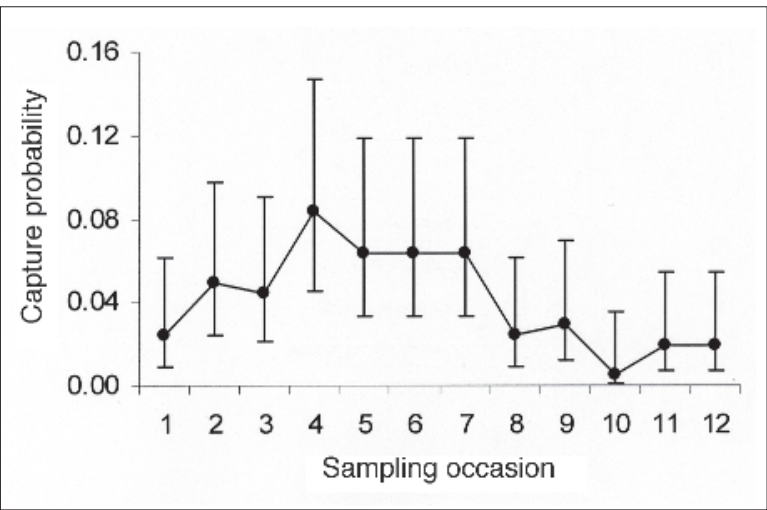

Figure 4. Estimated American eel capture probabilities and 95\% confidence intervals, based on eel pot sampling within the White Oak River, NC, in 2002. 
(95\% CI $=137-203)$ and density (300 $\mathrm{mm}$ and larger) was 12.7 per ha. Capture probabilities were similar in magnitude to estimates for grid \#1 and ranged from 0.05 to 0.19 (Fig. 5). The model with a constant capture probability was not considered feasible based on a $\triangle \mathrm{AICc}$ value greater than 10 .

Figure 5. Estimated timespecific capture probabilities and $95 \%$ confidence intervals for A m e ri c a n eels, based on eel pot sampling within the White Oak River, NC, in 2003. Timevarying estimates are shown for grid \#1 for comparison, although the model with a constant capture probability was judged to slightly better fit the data.

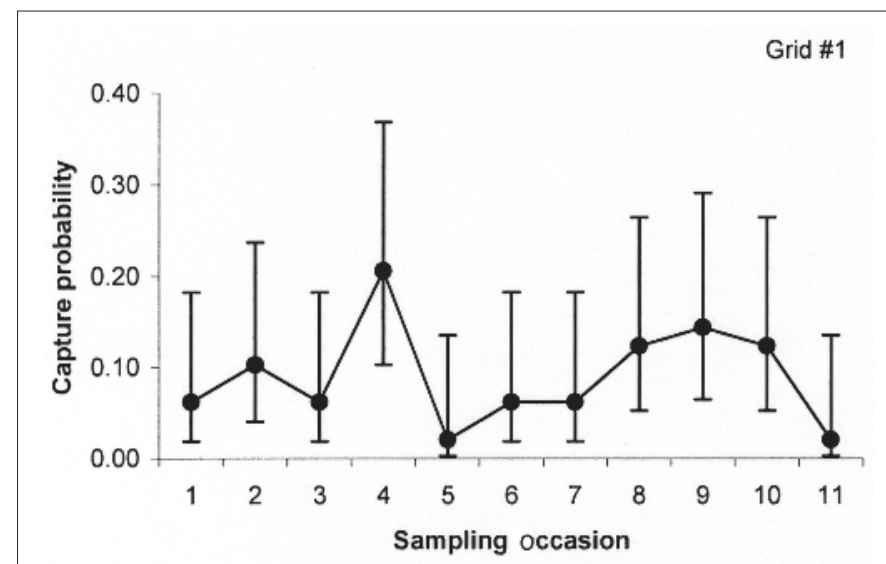

Grid \#2

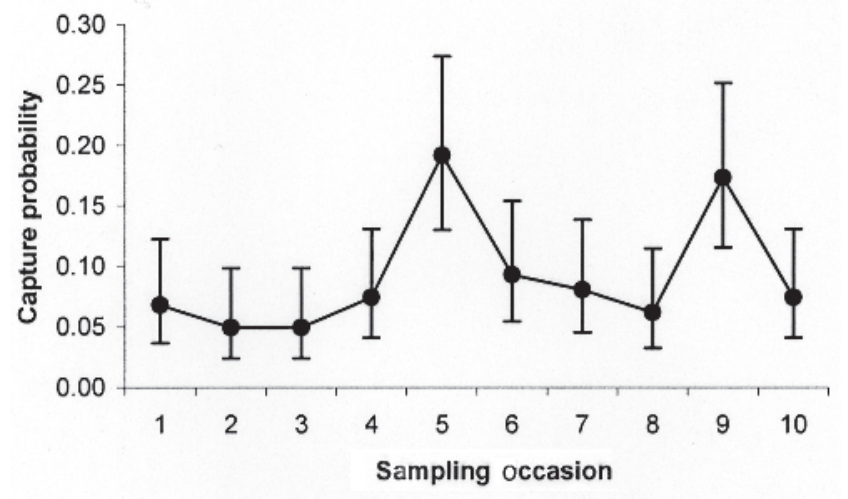

Grid \#3

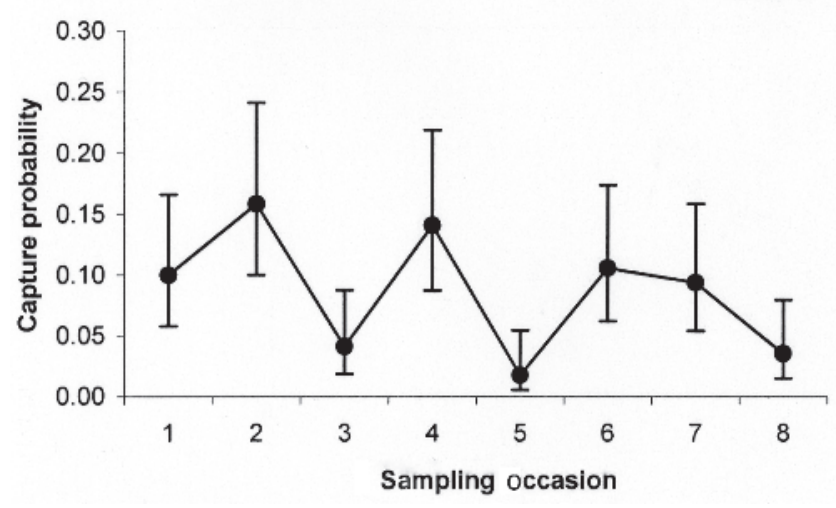


For grid \#3, the best model allowed capture probabilities to vary over time. For that model, estimated population size within the grid was 170.6 (95\% CI $=136-232)$ and density (300 mm and larger) was 13.8 per ha. Capture probabilities were similar in magnitude to estimates for grids \#1 and \#2 and ranged from 0.02 to 0.16 (Fig. 5). The model with a constant capture probability was not considered feasible based on a $\triangle \mathrm{AICc}$ value greater than 10 .

\section{Discussion}

American eels were widely distributed in the White Oak River estuary, based on eel pot and peeler pot captures. For example, we captured American eels at 59 of 60 locations within grids sampled during 2003. We did not detect any relationship between catch rate and water depth, although most sites sampled were shallow $(<3 \mathrm{~m})$. Another indication of a widespread distribution is that American eels tend to occur in peeler pots set at all depths (R. Howell, pers. comm.). Morrison and Secor (2004) sampled American eels at depths of 2-10 m within the Hudson River estuary. Within Chesapeake Bay, American eels occurred in trawl samples at depths ranging from 1 to $33 \mathrm{~m}$, although there was some indication of a preference for depths of 4-10 m (Geer 2003).

American eels captured in this study ranged from 224 to $709 \mathrm{~mm}$ total length. This size range is similar to that observed in other studies where 1.3$\mathrm{cm}$ wire mesh eel pots were used (Helfman et al. 1984, Morrison and Secor 2003). Helfman et al. (1984) compared eel-pot and rotenone samples from the Altamaha River, GA. They found size distributions to be similar above $250 \mathrm{~mm}$ and concluded that eel pot sampling was representative of the underlying population over the range $200-800 \mathrm{~mm}$. However, some results suggest that selectivity of eel pots may increase up to about $400 \mathrm{~mm}$. Our size distributions from eel-pot sampling were more or less flat from about 300 to $500 \mathrm{~mm}$, although the distributions were irregular due to small sample sizes. Modes of length distributions for Hudson River eel-pot sampling ranged from 380 to $460 \mathrm{~mm}$ (Morrison and Secor 2003). In comparison to these results, the mean length of American eels captured by trawling (with a 6.35-mm liner) in Chesapeake Bay from 1979 to 1999 was $268 \mathrm{~mm}$ (Geer 2003). Size selectivity in eel-pot sampling could be due to escape through the trap mesh sizes or to behavioral interactions.

American eels larger than about 500-550 mm were uncommon in our eel-pot and peeler-pot samples. A decrease in abundance at 500 to $550 \mathrm{~mm}$ has been observed in several other systems, and has been attributed to the outmigration of female silver eels (Morrison and Secor 2003, Oliveira 1999, Oliveira and McCleave 2000). We did not determine the sex of our captured American eels, although results of other studies (Barber 2004; Hansen and Eversole 1984; Krueger and Oliveira 1997; Morrison and Secor 2003; Oliveira 1997,1999) have shown that American eels with a total length greater than $400 \mathrm{~mm}$ are almost all females. 
American eels in the White Oak River estuary appeared to be in good condition based on the observed length-weight relationship. The estimated slope (3.41) was higher than the median slope (3.15) from other coastal or inland locations (Table 1). A value of 3 for the length-weight exponent indicates isometric growth (a consistent length-weight relationship), whereas a value greater than 3 indicates allometric growth with an increase in robustness over time. We did not account for gut fullness, which may have been artificially increased due to feeding within the trap. Weight measurements could be biased by about 2-6\% due to gut fullness (Helfman et al. 1984, Morrison and Secor 2003).

The movement that we observed for marked individuals was primarily over short distances. Both in the along-shore sampling of 2002 and the grid sampling of 2003, most recaptures occurred at sites close to the original tagging location. Limited movement of American eels has been observed in several estuarine sites along the east coast of the United States (Bozeman et al. 1985, Ford and Mercer 1986, Helfman et al. 1983, Morrison and Secor 2003). The level of short-term movement in the White Oak River estuary is probably related to the distribution of prey. Observations from peeler pot

Table 1. Estimated slope of length-weight relationship for American eels collected at sites from Newfoundland to Georgia.

\begin{tabular}{llc} 
Study & Location & Slope \\
\hline Gray and Andrews (1971) & Indian Pond, NF, Canada & 3.44 \\
& Topsail Barachois, NF, Canada & 3.44 \\
& Burnt Berry Brook, NF, Canada & 3.27 \\
Jessop (1987) & Salmon River, NF, Canada & 3.08 \\
& Medway, NS, Canada & 2.94 \\
& LaHave, NS, Canada & 3.06 \\
Oliveira and McCleave (2000) & Eel Brook Rivers, NS, Canada & 3.17 \\
& Sheepscot River, ME & 3.15 \\
& Medomak River, ME & 3.07 \\
Morrison and Secor (2003) & East Machias River, ME & 3.07 \\
Moser et al. (2000) & Pleasant River, ME & 3.07 \\
& Hudson River, New York & 3.20 \\
& Roanoke River - inland, NC & 3.56 \\
& Currituck Sound - northern, NC & 3.48 \\
& Currituck Sound - southern, NC & 2.98 \\
& Pasquotank River mouth, NC & 3.26 \\
& Yeopim River, NC & 3.34 \\
& Roanoke Sound, NC & 3.04 \\
& Chocowinity Bay, NC & 3.16 \\
& Neuse River, NC & 3.04 \\
This study & White Oak River, NC & 3.20 \\
Harrell and Loycano (1982) & Beaufort area, NC & 3.14 \\
Michener and Eversole (1983) & Cape Fear River - inland, NC & 2.94 \\
Hansen and Eversole (1984) & Chite Oak River estuary & 3.41 \\
Helfman et al. (1984) & Cooper River, SC & 3.34 \\
\hline
\end{tabular}


fishing indicate that American eels shift their distribution within the estuary based on changes in salinity and prey species such as blue crabs (R. Howell, pers. comm.). Bozeman et al. (1985) suggested that movement of American eels may be reduced in estuaries compared to temperate freshwater lakes because of the high productivity of estuaries.

Our estimates of population density from grid sampling in 2003 ranged from 4.0-13.8 per ha. The estimates would apply to American eels roughly $300 \mathrm{~mm}$ and larger, based on observed size distributions. We obtained a lower density estimate (2.0 per ha) in 2002, but there was greater uncertainty about the area sampled. The grid sampling in 2003 provides a clearer basis for the default area sampled. Our density estimates from grid sampling are similar to those obtained from the Hudson River estuary (1-30 per ha; Morrison and Secor 2004). Both studies are based on eel-pot sampling of estuarine shoal waters with bottom sediments of fine clay and silt. Both sets of estimates are substantially lower than estimates from other (smaller) streams and rivers, including some estuaries. Oliveira and McCleave (2000) used three-pass electrofishing within blocked sections of four wadeable rivers in Maine, and obtained estimates ranging from 840 to 2180 per ha. Their estimates included all individuals greater than $100 \mathrm{~mm}$ total length. Oliveira (1997) used five-pass electrofishing within blocked sections of a wadeable Rhode Island river and obtained estimates ranging from 450 to 3230 per ha. His estimates included all individuals greater than $160 \mathrm{~mm}$ total length. Ford and Mercer (1986) used capture-recapture methods and estimated that the density of American eels $>150 \mathrm{~mm}$ was 875 per ha in several Massachusetts tidal creeks. The average density of American eels in wadeable Maryland tributaries to Chesapeake Bay, based on twopass electrofishing of blocked stream segments, was 430 per ha (Wiley et al. 2004). Average densities for medium (250-374 mm) and large (> 374 $\mathrm{mm}$ ) American eels in wadeable coastal plain streams in Virginia were 370 and 52 per ha, respectively (Smogor et al. 1995). Sampling was done using two passes with an electric seine in blocked sections of streams. The estimated density of American eels $\geq 200 \mathrm{~mm}$ in a Georgia tidal creek, based on capture-recapture methods, was 182 per ha (Bozeman et al. 1985). As noted by Morrison and Secor (2004) for the Hudson River, any adjustments for the size range of American eels sampled would not account for the substantial difference between the White Oak estimates and those of smaller systems.

The difference in density between the White Oak River estuary and other systems (except for the Hudson River estuary) may be even greater than estimated here, if immigration into our study areas was a significant bias. In 2003, 5 of 35 recaptures at grid \#3 were marked at the other two grids, at distances of 0.8 and $1.7 \mathrm{~km}$. This movement between grids could be strictly random and could have occurred prior to the start of grid sampling, but likely indicates that the baited pots are sampling a larger area 
than defined by the grid. Immigration would cause the closed-model population estimates to be too high because the area sampled would be greater than the assumed size. The movement between grid sites that we detected in 2003 suggests a limited response to the presence of baited eel pots. Also, shorelines provided boundaries that may have limited migration somewhat, particularly for grids 1 and 2. On the other hand, the grids were separated by $0.8-2.5 \mathrm{~km}$, so a higher rate of immigration could have occurred for unmarked animals closer to each grid. Morrison and Secor (2004) observed substantial immigration into grids of baited pots in the Hudson River estuary, and they used open population models to allow for immigration into their grids. We did not consider open models to be a feasible alternative in our study because of our relatively low capture probabilities. We also did not account for the trap-shy behavior reported by Morrison and Secor (2004). Our recapture rates were similar for American eels at large for 1-3 days, whereas Morrison and Secor (2004) found a lower rate of recapture one day after tagging. Possible explanations for the trap-shy behavior that they observed were a short-term effect of the anesthetic, reduced interest in feeding after feeding in the trap, and overlooking the brands (Morrison and Secor 2004). Bozeman et al. (1985) reported a significantly longer interval from tagging to recapture for American eels with full (mean $2.83 \mathrm{~d}$ ) versus empty (mean $2.02 \mathrm{~d}$ ) guts.

It does not appear that harvest would account for the relatively low density estimates in the White Oak and Hudson rivers, compared to other systems. Commercial fishing for American eels is limited in the White Oak River (R. Howell, pers. comm.), and there is only a small bait fishery in the Hudson River (Morrison and Secor 2003). It may be that estuarine shoal areas with soft sediments support lower densities of American eels than other habitat types, perhaps due to the low habitat complexity. Geer (2003) reported that trawl catches of American eels in Chesapeake Bay tended to occur in association with detritus, hydroid, and shell habitats. Also, catches were considerably higher within tributaries near or above the freshwater interface compared to the mainstem Chesapeake Bay. Wiley et al. (2004) reported that sites in Maryland streams with only one or two velocity-depth regimes (e.g., only deep-slow, shallow-slow) had significantly lower densities than sites with more velocity-depth regimes. It would seem reasonable that the amount of cover would be an important variable, although Wiley et al. (2004) did not detect a relationship between American eel abundance and the amount of instream habitat. Smogor et al. (1995) detected a positive relationship between American eel density and cover for small (61-249 mm) and medium-sized (250-374 mm) but not large (> 374 $\mathrm{mm})$ American eels.

For future capture-recapture studies, a key step would be to minimize the biases associated with use of baited pots, such as immigration into the study area (bait attraction) and trap-shy or trap-happy behavior. Carton and 
Montgomery (2003) found that Anguilla dieffenbachii Steindachner (longfin eel)and Anguilla australis Richardson (shortfin eel) were attracted to the scent of bait, and that initial detection of a food odor resulted in direct upstream movement toward the odor source. The eels in their study appeared to detect and track the margins of the odor plume. Capture-recapture studies could be done using unbaited fyke nets, which are inexpensive and easy to use (Jellyman and Graynoth 2005). Unbaited fyke nets were found to be relatively ineffective for trapping longfin and shortfin eels (Jellyman and Graynoth 2005), but have proven effective in American eel research in the Maritime Provinces (Cairns et al. 2004; D. Cairns, Fisheries and Oceans Canada, Charlottetown, PEI, Canada, pers. comm.).

Another approach for reducing these biases would be to use different methods for marking and recapture sampling (Morrison and Secor 2004, Ricker 1975). For example, baited pots or traps have been used in most estuarine studies targeting American eels (e.g., Bozeman et al. 1985, Ford and Mercer 1986, Morrison and Secor 2003), but a bottom trawl using a 6.35-mm liner regularly captured American eels in the Chesapeake Bay (Geer 2003). Another approach for reducing biases associated with baited pots would be to use permanent marks (e.g., passive integrated transponder or coded wire tags) so that sampling could be conducted over short periods at longer intervals (e.g., one overnight set per week). This would eliminate bias due to a short-term trap-shy behavior as well as gradual immigration into a study grid due to the bait plume.

One of the key gaps in information listed in the Fishery Management Plan for American eel (ASMFC 2000) is regarding the impacts of fishing. Traditional stock assessment methods such as catch-at-age analysis (Hilborn and Walters 1992) are not feasible because age composition is not routinely determined for American eel catches. Spatially-based management using capture-recapture methods may be a more practical alternative. For example, Morrison and Secor (2004) used density estimates from grid sampling to estimate overall abundance of American eels in the Hudson River estuary (for areas 2-10 $\mathrm{m}$ deep). Capture-recapture estimates provide a much stronger basis for management than relative abundance indices, because population density and harvest within a particular area can be used to estimate the harvest rate. Management can then be based on the difference between the current harvest rate and a target rate, based on American eel life-history characteristics. A similar approach has been proposed for management of the A. anguilla Linnaeus (European eel), based on an estimated carrying capacity of $10 \mathrm{~kg}$ per ha in freshwater habitats (ICES 2001). The management goal in that approach would be to maintain spawning escapement of silver eels above some percentage (e.g., 30\%) of carrying capacity (ICES 2001). It is interesting to note that the density estimates for the White Oak River estuary (4-14 per ha) would correspond to about 1-3 kg per ha, based on the average weight of American eels captured during 2002-2003. 
The first step in carrying out this spatially-based management approach would be to develop geographic information systems (GIS) layers for annual harvest by habitat type or management unit. Capture-recapture studies within these habitat or management units would then provide the quantitative information needed for effective management of this important species.

\section{Acknowledgments}

We thank the US Forest Service who provided funding for this research. We also appreciate the contributions of field technicians P. Hubert, N. Jeffers, S. Minis, and A. Price. Helpful comments on an earlier version of this manuscript were provided by D. Fox and W. Starnes. Advice and assistance was also provided by J. Armstrong, J. Crutchfield, R. Graham, D. Hewitt, B. Jessop, C. Oakley, W. Patrick, W. Pine, K. Pollock, A. Read, P. Read, D. Secor, C. Vida, M. Whitacre, and W. Wise. The College of Agriculture and Life Sciences, NC State University, assisted with travel expenses for the field studies. We greatly appreciate the assistance of R. and G. Howell of Swansboro, who provided logistical support, eels captured during crabbing operations, and valuable background information about American eels and commercial fishing operations.

\section{Literature Cited}

Atlantic States Marine Fisheries Commission (ASMFC). 2000. Interstate fishery management plan for American eel (Anguilla rostrata). Fishery Management Report 36, Atlantic States Marine Fisheries Commission, Washington, DC. 79 pp.

Barber, R. 2004. Sex ratio of silver American eels (Anguilla rostrata) migrating out of two southern Delaware streams. M.Sc. Thesis. University of Delaware, Newark, DE. 93 pp.

Bozeman, E.L., G.S. Helfman, and T. Richardson. 1985. Population size and home range of American eels in a Georgia tidal creek. Transactions of the American Fisheries Society 114:821-825.

Burnham, K.P., and D.R. Anderson. 1998. Model Selection and Inference: A practical Information-Theoretic Approach. Springer-Verlag, New York, NY. 353 pp.

Burnham, K.P., D.R. Anderson, G.C. White, C. Brownie, and K.H. Pollock. 1987. Design and analysis methods for fish survival experiments based on releaserecapture data. American Fisheries Society Monograph 5, Bethesda, MD. 437 pp.

Busch, W.D.N., S.J. Lary, C.M. Castilione, and R.P. McDonald. 1998. Distribution and availability of Atlantic Coast freshwater habitats for American eel (Anguilla rostrata). Administrative Report No. 98-2, US Fish and Wildlife Service. Amherst, NY. 28 pp.

Cairns, D.K., J.C. Shiao, Y. Iizuka, W.-N. Tzeng, and C.D. MacPherson. 2004. Movement patterns of American eels in an impounded watercourse, as indicated by otolith microchemistry. North American Journal of Fisheries Management $24: 452-458$.

Carton, A.G., and J.C. Montgomery. 2003. Evidence of a reheotactic component in the odour search behaviour of freshwater eels. Journal of Fish Biology 62:501-516. 
Cooch, E., and G. White. 2003. Program MARK: A gentle introduction. Available online at http://www.phidot.org/software/mark/docs/book/. Accessed 7/27/05.

Dixon, D.A. (Ed.). 2003. Biology, Management, and Protection of Catadromous Eels. American Fisheries Society, Symposium 33, Bethesda, MD. 388 pp.

Ford, T., and E. Mercer. 1986. Density, size distribution, and home range of American eels, Anguilla rostrata, in a Massachusetts salt marsh. Environmental Biology of Fishes 17:309-314.

Geer, P.J. 2003. Distribution, relative abundance, and habitat use of American eel Anguilla rostrata in the Virginia portion of the Chesapeake Bay. American Fisheries Society Symposium 33:101-115.

Gray, R.W., and C.W. Andrews. 1971. Age and growth of the American eel (Anguilla rostrata (Le Sueur)) in Newfoundland waters. Canadian Journal of Zoology 49:121-128.

Hansen, R.A., and A.G. Eversole. 1984. Age, growth, and sex ratio of American eels in brackish-water portions of a South Carolina river. Transactions of the American Fisheries Society 113:744-749.

Haro, A., W. Richkus, K. Whalen, A. Hoar, W. Dieter Busch, S. Lary, T. Brush, and D. Dixon. 2000. Population decline of the American eel: Implications for research and management. Fisheries (Bethesda) 25:7-16.

Harrell, R.M., and L.A. Loycano, Jr. 1982. Age, growth, and sex ratios of the American eel in the Cooper River, South Carolina. Proceedings of the Annual Conference, Southeastern Association of Fish and Wildlife Agencies 34:349-359.

Helfman, G.S., D.L. Stoneburner, E.L. Bozeman, P.A. Christian, and R. Whalen. 1983. Ultrasonic telemetry of American eel movements in a tidal creek. Transactions of the American Fisheries Society 112:105-110.

Helfman, G.S., E.L. Bozeman, and E.B. Brothers. 1984. Size, age, and sex of American eels in a Georgia river. Transactions of the American Fisheries Society 113:132-141.

Helfman, G.S., D.E. Facey, L.S. Hales, Jr., and E.L. Bozeman. 1987. Reproductive ecology of the American eel. American Fisheries Society Symposium $1: 42-56$.

Hilborn, R., and C.J. Walters. 1992. Quantitative Fisheries Stock Assessment: Choice, Dynamics, and Uncertainty. Chapman and Hall, New York, NY. 570 pp.

Hooge, P.N., and B. Eichenlaub. 1997. Animal movement extension to arcview. ver. 1.1. Alaska Science Center - Biological Science Office, US Geological Survey, Anchorage, AK.

International Council for the Exploration of the Sea (ICES). 2001. Report of the EIFAC/ICES Working Group on eels. ICES, CM 2001/ACFM:03, Copenhagen, Denmark. Available online at http://www.ices.dk/reports/acfm/2000/wgeel/ wgeel00.pdf. Accessed 7/27/05.

Jellyman D.J., and E. Graynoth. 2005. The use of fyke nets as a quantitative capture technique for freshwater eels (Anguilla spp.) in rivers. Fisheries Management and Ecology 12:237-247.

Jessop, B.M. 1987. Migrating American eels in Nova Scotia. Transactions of the American Fisheries Society 116:161-170.

Jessop, B.M. 2000. Estimates of population size and instream mortality rate of American eel elvers in a Nova Scotia river. Transactions of the American Fisheries Society 129:514-526. 
Krueger, W.K., and K. Oliveira. 1997. Sex, size, and gonad morphology of silver American eels, Anguilla rostrata. Copeia 1997:415-420.

McCleave, J.D., R.C. Kleckner, and M. Castonguay. 1987. Reproductive sympatry of American and European eels and implications for migration and taxonomy. American Fisheries Society Symposium 1:286-297.

Michener, W.K., and A.G. Eversole. 1983. Age, growth, and sex ratio of American eels in Charleston Harbor, South Carolina. Proceedings of the Annual Conference, Southeastern Association of Fish and Wildlife Agencies 37:422-431.

Morrison, W.E., and D.H. Secor. 2003. Demographic attributes of yellow-phase American eels (Anguilla rostrata) in the Hudson River estuary. Canadian Journal of Fisheries and Aquatic Sciences 60:1487-1501.

Morrison, W.E., and D.H. Secor. 2004. Abundance of yellow-phase American eels in the Hudson River estuary. Transactions of the American Fisheries Society 133:894-908.

Moser, M.L., W.S. Patrick, and J.U. Crutchfield, Jr. 2000. Incidence of Anguillicola crassus infection of American eels in North Carolina waters. Final Report to North Carolina Fisheries Research Grant Program, Project Number 99EP-11. 42 pp. Available online at http://www.ncseagrant.org/elements/research_files/ 99EP11.PDF. Accessed 5/31/06.

North Carolina Department of Environment and Natural Resources (NCDENR). 2001. White Oak River basinwide water quality plan. North Carolina Department of Environment and Natural Resources, Raleigh, NC. 246 pp.

North Carolina Department of Environment and Natural Resources (NCDENR). 2005. Basinwide assessment report: White Oak River basin. North Carolina Department of Environment and Natural Resources, Raleigh, NC. 113 pp.

Oliveira, K. 1997. Movements and growth rates of yellow-phase American eels in the Annaquatucket River, Rhode Island. Transactions of the American Fisheries Society 126:638-646.

Oliveira, K. 1999. Life-history characteristics and strategies of the American eel, Anguilla rostrata. Canadian Journal of Fisheries and Aquatic Sciences 56:795-802.

Oliveira, K., and J.D. McCleave. 2000. Variation in population and life-history traits of the American eel, Anguilla rostrata, in four rivers in Maine. Environmental Biology of Fishes 59:141-151.

Otis, D.L., K.P. Burnham, G.C. White, and D.R. Anderson. 1978. Statistical inference from capture data on closed animal populations. Wildlife Monograph 62. $135 \mathrm{pp}$.

Ricker, W.E. 1975. Computation and interpretation of biological statistics of fish populations. Fisheries Research Board of Canada, Ottawa, ON, Canada. Bulletin 191. $382 \mathrm{pp}$.

Smogor, R.A., P.L. Angermeier, and C.K. Gaylord. 1995. Distribution and abundance of American eels in Virginia streams: Tests of null models across spatial scales. Transactions of the American Fisheries Society 124:789-803.

Sorensen, P.W., M. Bianchini, and H.E. Winn. 1983. Individually marking American eels by freeze branding. Progressive Fish-Culturist 45:62-63.

Tesch, F.W. 1977. The Eel: Biology and Management of Anguillid Eels. Chapman and Hall/ John Wiley and Sons, New York, NY. 408 pp. 
Wiley, D.J., R.P. Morgan II, R.H. Hilderbrand, R.L. Raesly, and D.L. Shumway. 2004. Relations between physical habitat and American eel abundance in five river basins in Maryland. Transactions of the American Fisheries Society 133:515-526.

Wirth, T., and L. Bernatchez. 2003. Decline of North Atlantic eels: A fatal synergy? Proceedings of the Royal Society of London, Series B: Biological Sciences 270(1516):681-688. 